\title{
The bilateral bump of the lower jaw - a case of mandibular tori
}

\begin{abstract}
Torus or Tori (plural) is a benign bone growth in the mouth, and in $90 \%$ of the cases seen on both the left and right sides of the oral cavity, making it an overwhelmingly bilateral condition. Mandibular tori are asymptomatic bony exophytic growths that are present on the lingual surface of the mandible, opposite to the premolars. Although asymptomatic, it can sometimes result in complications such as interference with speech, tongue positioning, prosthetic reasons, poor oral hygiene and traumatic ulceration of mucosal surface.
\end{abstract}

Volume 9 Issue 2 - 2018

\author{
Geon Pauly, Roopashri Rajesh Kashyap, \\ Raghavendra Kini, Prasanna Kumar Rao, \\ Gowri P Bhandarkar, Devika Shetty \\ Department of Oral Medicine and Radiology, A.J Institute of \\ Dental Sciences, India
}

Correspondence: Geon Pauly N, Postgraduate student, Department of Oral Medicine and Radiology, A.J Institute of Dental Sciences, Kuntikana, NH-66. Mangaluru - 575004, Karnataka, India, Tel 918905102696, Email geonpauly@gmail.com

Received: February 20, 2018 | Published: April 05, 2018

\section{Case report}

A 29-year-old medically fit patient reported to our department with a chief complaint of stains and deposits of teeth. His medical, dental, family histories were non-contributory. On intra-oral examination, as an incidental finding, bilateral bony exostosis was seen in the floor of the mouth region extending from second premolar to first molar region on both the sides (Figure 1). The swelling was covered with a thin, intact mucosa with colour same as the adjacent mucosa and was non-tender and hard in consistency upon palpation. Patient was educated about the incidental pathology found and was then sent to the department of Periodontics for the required oral prophylaxis.

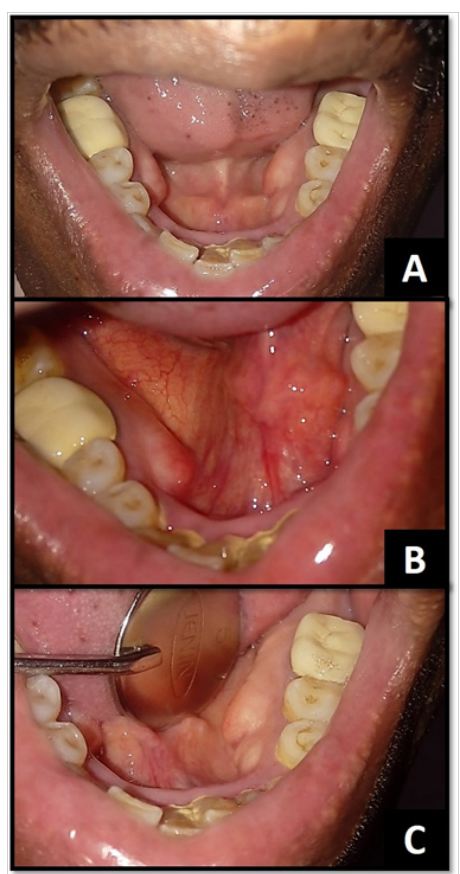

Figure I Presence of mandibular tori,A: Bilateral, B: Right side, C: Left side

\section{Discussion}

The tori, meaning 'to stand out' or 'lump', are exostosis that are formed by a dense cortical and limited amount of bone marrow, and they are covered with a thin and poorly vascularised mucosa. ${ }^{1}$ Literature states the prevalence of these anomalies increases with age; and found that tori develop in the 2nd or 3rd decade of life, with an initial phase of rapid growth. The growth rate is then thought to decrease with age, but never stops. ${ }^{2}$ Genetic factors, environmental factors, masticatory hyper-function and continued growth are the current postulated etiologic factors for this entity. ${ }^{3}$ Tori mandibularis can be nodular, unilateral or bilateral, single or multiple. Depending on anatomic location they are classified as torus mandibularis, torus palatines and buccal bone exostosis. Torus mandibularis arises in the lingual side of mandible in relation to premolars above the mylohyoid ridge. Tori can be categorized by their appearance and shape as: Flat, Spindle, Nodular and Lobular types. ${ }^{4}$ Mandibular tori are usually a clinical finding with no treatment necessary until there is complain of pain, speech defect, interference with prosthetic planning or even cases of cancer phobia where in verbal counselling does not get the job done. ${ }^{5}$ So to conclude, torus mandibularis is asymptomatic and does not have malignant transformation potential and so does not usually require any surgical treatment, but only re-assurance unless symptomatic or hinder some.

\section{Acknowledgements}

Brilliant Raphael \& Vijayendranath Nayak.

\section{Conflict of interest}

None.

\section{References}

1. Rastogi K, Verma SK, Bhushan R. Surgical Removal of Mandibular Tori and its Use as an Autogenous Graft. BMJ Case Rep. 2013;Bcr2012008297.

2. Pradhan MS, Patil SN, Uttawar VS, et al. Multiple Mandibular Tori: Three Case Reports and Review. IOSR Journal of Dental and Medical Sciences. 2017;16(6):26-9. 
3. Nair AS, Kurien NM, Kumar LKS, et al. Large Lingual Tori: A Clinical Case Report. Medical Case Reports and Images. 2017;1(5):1-6.

4. Sangwan A, Sharma K. Mandibular Tori - A Case Report \& Review. International Journal of Contemporary Dentistry. 2011;2(5): 125-127.
5. Garcia-Garcia AS, Martinez-Gonzalez JM, Gomez-Font R, et al. Current Status of the Torus and Torus Mandibularis. Oral Med Oral Pathol Oral Cir Bucal. 2010;15(2):353-60. 